\title{
RESEARCH
}

Open Access

\section{Health economic evaluations of sepsis interventions in critically ill adult patients: a systematic review}

\author{
Alisa M. Higgins ${ }^{1 *} \mathbb{D}$, Joanne E. Brooker ${ }^{1}$, Michael Mackie ${ }^{1}$, D. Jamie Cooper ${ }^{1,2}$ and Anthony H. Harris ${ }^{3}$
}

\begin{abstract}
Background: Sepsis is a global health priority. Interventions to reduce the burden of sepsis need to be both effective and cost-effective. We performed a systematic review of the literature on health economic evaluations of sepsis treatments in critically ill adult patients and summarised the evidence for cost-effectiveness.

Methods: We systematically searched MEDLINE, Embase, and the Cochrane Library using thesaurus (e.g. MeSH) and free-text terms related to sepsis and economic evaluations. We included all articles that reported, in any language, an economic evaluation of an intervention for the management of sepsis in critically ill adult patients. Data extracted included study details, intervention details, economic evaluation methodology, and outcomes. Included studies were appraised for reporting quality using the Consolidated Health Economic Evaluation Reporting Standards (CHEERS) checklist.

Results: We identified 50 records representing 46 economic evaluations for a variety of interventions including antibiotics $(n=5)$, fluid therapy $(n=2)$, early goal-directed therapy and other resuscitation protocols $(n=8)$, immunoglobulins $(n=2)$, and interventions no longer in clinical use such as monoclonal antibodies $(n=7)$ and drotrecogin alfa ( $n=13)$. Twelve (26\%) evaluations were of excellent reporting quality. Incremental costeffectiveness ratios (ICERs) ranged from dominant (lower costs and higher effectiveness) for early goal-directed therapy, albumin, and a multifaceted sepsis education program to dominated (higher costs and lower effectiveness) for polymerase chain reaction assays (LightCycler SeptiFast testing MGRADE ${ }^{\circledR}$, SepsiTest ${ }^{\mathrm{TM}}$, and IRIDICA BAC BSI assay). ICERs varied widely across evaluations, particularly in subgroup analyses.

Conclusions: There is wide variation in the cost-effectiveness of sepsis interventions. There remain important gaps in the literature, with no economic evaluations identified for several interventions routinely used in sepsis. Given the high economic and social burden of sepsis, high-quality economic evaluations are needed to increase our understanding of the cost-effectiveness of these interventions in routine clinical practice and to inform decision makers.
\end{abstract}

Trial registration: PROSPERO CRD42018095980

Keywords: Sepsis, Septic shock, Cost-effectiveness, Economic evaluation, Systematic review

\footnotetext{
* Correspondence: lisa.higgins@monash.edu

${ }^{1}$ Australian and New Zealand Intensive Care Research Centre, Department of Epidemiology and Preventive Medicine, Monash University, 553 St Kilda Rd, Melbourne, Victoria 3004, Australia

Full list of author information is available at the end of the article
}

(c) The Author(s). 2020 Open Access This article is distributed under the terms of the Creative Commons Attribution 4.0 International License (http://creativecommons.org/licenses/by/4.0/), which permits unrestricted use, distribution, and reproduction in any medium, provided you give appropriate credit to the original author(s) and the source, provide a link to the Creative Commons license, and indicate if changes were made. The Creative Commons Public Domain Dedication waiver (http://creativecommons.org/publicdomain/zero/1.0/) applies to the data made available in this article, unless otherwise stated. 


\section{Background}

Sepsis is recognised globally as a health priority. In 2017, the World Health Assembly and the World Health Organisation adopted a resolution to improve the prevention, diagnosis, and management of sepsis [1]. The resolution urged the United Nation Member States to implement measures to reduce both the human and health economic burden of sepsis [1]. Crude incidence estimates extrapolated from data gathered in the United States of America (USA) indicate there could be 15-19 million cases of sepsis every year worldwide [1]. Septicaemia was the most expensive condition treated in USA hospitals in 2013, with a financial burden exceeding US\$23 billion [2].

It is critical to understand the cost-effectiveness of interventions designed to improve outcomes from sepsis. While there have been numerous systematic reviews summarising the evidence for effectiveness of individual interventions including early goal-directed therapy (EGDT) [3-5], fluid therapy [6-8], and corticosteroids [9-11], decision makers are also interested in which interventions deliver value for money in the context of limited health care resources. Economic evaluations assist decision making as they assess both costs and benefits, enabling a more complete consideration of the value of an intervention-what additional benefit is provided for what additional cost [12]. In 2006, Talmor and colleagues conducted a systematic review of the cost effectiveness literature in critical care medicine and found four economic evaluations of sepsis interventions, all of which were drotrecogin alpha (activated) [13]. Since that time, numerous other interventions for the treatment of sepsis have been evaluated. Wilcox and colleagues recently published a systematic review of the cost effectiveness literature in critical care medicine; however, their review was limited to intensive care interventions and English language publications [14]. Given the global burden of sepsis, we conducted a contemporary systematic review of economic evaluations of interventions for sepsis management in critically ill adult patients, including interventions delivered outside of the intensive care setting (such as in the emergency department) and articles published in languages other than English. Our objective was to summarise the evidence for the costeffectiveness of sepsis interventions and to identify gaps in the existing literature.

\section{Methods}

The protocol for this systematic review was registered on PROSPERO (CRD 42018095980) prior to the finalisation of the search strategies. The review was guided by the Preferred Reporting Items for Systematic Reviews and Meta-Analyses (PRISMA) statement [15].

\section{Search strategy}

A comprehensive search of major electronic databases (Ovid MEDLINE, including Epub Ahead of Print, InProcess and Other Non-Indexed Citations; Ovid Embase Classic+Embase; and the Cochrane library, including the Health Technology Assessment database and the National Health Service Economic Evaluation Database) was conducted up to 17 July 2018 with no restrictions on the year of publication or language. Thesaurus (e.g. Medical Subject Headings; Emtree) and free-text terms relevant to sepsis and economic evaluations were used, including sepsis, septicemia, septic shock, economic evaluation, cost-benefit, cost-utility, cost-effectiveness, cost-minimisation, and critical care (full details of the search strategies are available in Additional file 1). The reference lists of included articles were also screened for any additional relevant articles.

\section{Study selection}

All screening was performed in duplicate (AMH, JB), with discrepancies resolved by discussion with a third reviewer (MM). Screening was performed in two stages. Initially assessing titles and abstracts, we excluded articles that clearly did not meet eligibility criteria. The full text of the remaining articles was then examined. Reasons for exclusion were captured at the full article review stage.

We included all articles that reported, in any language, an economic evaluation of an intervention for the management of sepsis in critically ill adult patients. Articles published in a language other than English were translated by a medical or public health professional fluent in both English and the language of publication. An economic evaluation was defined as the comparative analysis of alternative interventions in terms of both costs (resource use) and consequences (outcomes, effects) [16]. Full economic evaluations include studies conducting cost-benefit analyses, cost-utility analyses, and costeffectiveness analyses [12]. Cost-minimisation analyses were included where the authors pre-specified that a cost-minimisation analysis would be performed where no significant difference in outcomes was found. We included economic evaluations that were trial-based (deriving clinical and resource data from a single study) and model-based (incorporating data from various sources). Economic analyses which focused solely on costs and resources used, or which did not entail a comparator, were excluded.

Articles were also excluded for the following reasons: available in abstract form only (for example conference abstracts); reviews of existing economic evaluations that did not present new data; included patients without sepsis and results were not available separately for the sepsis subgroup; patient group was neonates or children or a mixed cohort where results were not available for the 
adult subgroup; or intervention was for the diagnosis of sepsis only.

\section{Data extraction and quality assessment}

Two reviewers (AMH, JB) performed data extraction independently using data extraction forms in Covidence (Veritas Health Innovation, Melbourne, Australia). Discrepancies were resolved by discussion with a third reviewer (MM). Data extracted included study details (author, year, country, funding source), patients' details (diagnosis, severity of illness, age), intervention details, economic evaluation methodology (time horizon, currency, discounting, perspective, type of evaluation, data sources, sensitivity analysis), and outcomes. Outcomes extracted included cost-effectiveness measures using an incremental cost-effectiveness ratio (ICER; for example cost per outcome, including cost per quality adjusted life year [QALY] and cost per life year gained) or a probability of cost-effectiveness; total costs; and health outcomes including mortality and quality of life. Interventions were reported to be dominant when they were associated with lower costs and greater effectiveness compared to the comparator, while they were reported to be dominated when associated with higher costs and lower effectiveness. Survival rates, where reported, were converted to mortality rates for consistency of outcome presentation. Corresponding authors were contacted where data required clarification. Where evaluations presented both nondiscounted and discounted results, we reported the discounted results.

Quality assessment of the reporting of all included economic evaluations was performed independently by two reviewers (AMH, JB) using the 24-item Consolidated Health Economic Evaluation Reporting Standards (CHEERS) checklist $[17,18]$ with discrepancies resolved by discussion. A score out of 24 (or the number of applicable items) was calculated for each evaluation, with each item on the checklist assigned one point where the article adequately met the criterion. Using the method described by Hope et al. [19], a half point was awarded where the article partially filled the criterion. Where an evaluation was reported in more than one publication, both publications were used to assess reporting quality, with the evaluation being assigned the highest score from either publication for each CHEERS item. A percentage score for each evaluation was then calculated. Evaluations scoring $\geq 85 \%$ were categorised as having excellent reporting quality, 70 to $<85 \%$ as very good quality, 55 to $<70 \%$ as good quality, and evaluations scoring $<55 \%$ were classified as poor quality [19].

\section{Data synthesis}

Studies were summarised according to the intervention evaluated. Economic evaluations of early goal-directed therapy (EGDT) for sepsis were a pre-defined subgroup, as were economic evaluations for patients meeting the criteria for septic shock. To enable comparison of results from different countries and price years, costs were converted to US dollars (USD) within the year they were performed using purchasing power parities [20] and then inflated to 2018 USD using the consumer price index [21]. A qualitative assessment of heterogeneity among trials was performed to determine whether quantitative synthesis of study results would be appropriate.

\section{Results}

A total of 2292 records were identified from the initial search, with 1799 records remaining after removal of duplicates. Two reviewers (AMH, JB) screened titles and abstracts for all records, and a total of 199 records were retrieved for full text evaluation. An additional two records meeting the criteria were identified from reference list reviews of the included publications. A total of 50 records representing 46 health economic evaluations met criteria for inclusion (Fig. 1). Four economic evaluations had two publications each: three with health technology assessments in addition to a journal article; one with a journal article and a subsequent erratum. Records excluded following full text evaluation, along with the reason for exclusion, are listed in Additional file 2.

\section{Study characteristics}

The characteristics of included economic evaluations are summarised in Table 1 (further details are available in Additional file 3). The first evaluation was published in 1991 [64], with the majority (72\%) of the evaluations published in the past 15 years (Fig. 2). All evaluations published more than 15 years ago focused on interventions that were subsequently shown to have no clinical benefit and are no longer used in the treatment of sepsis (monoclonal antibodies [HA-1A and E5] and drotrecogin alfa [activated]).

Five evaluations examined antibiotic interventions [22-26], two examined fluid therapies [27, 28], eight examined EGDT or other (primarily emergency department [ED]-based) resuscitation protocols [35-42, 71], three examined procalcitonin algorithms [29-31], two examined immunoglobulin therapies [32-34], four examined methods of pathogen identification [43-46], one examined point of care lactate testing [47], and one examined immediate ICU admission [48]. The remaining 20 evaluations examined interventions no longer used in clinical practice-13 examined drotrecogin alfa (activated) (51-64), and seven examined monoclonal antibodies [64-70]. Most evaluations were cost-effectiveness and/or cost-utility analyses (44/46, 96\%), with $2(4 \%)$ cost-minimisation analyses (Table 1). Fourteen (30\%) evaluations conducted both cost-effectiveness and costutility analyses (Table 1). Eighteen of the evaluations 


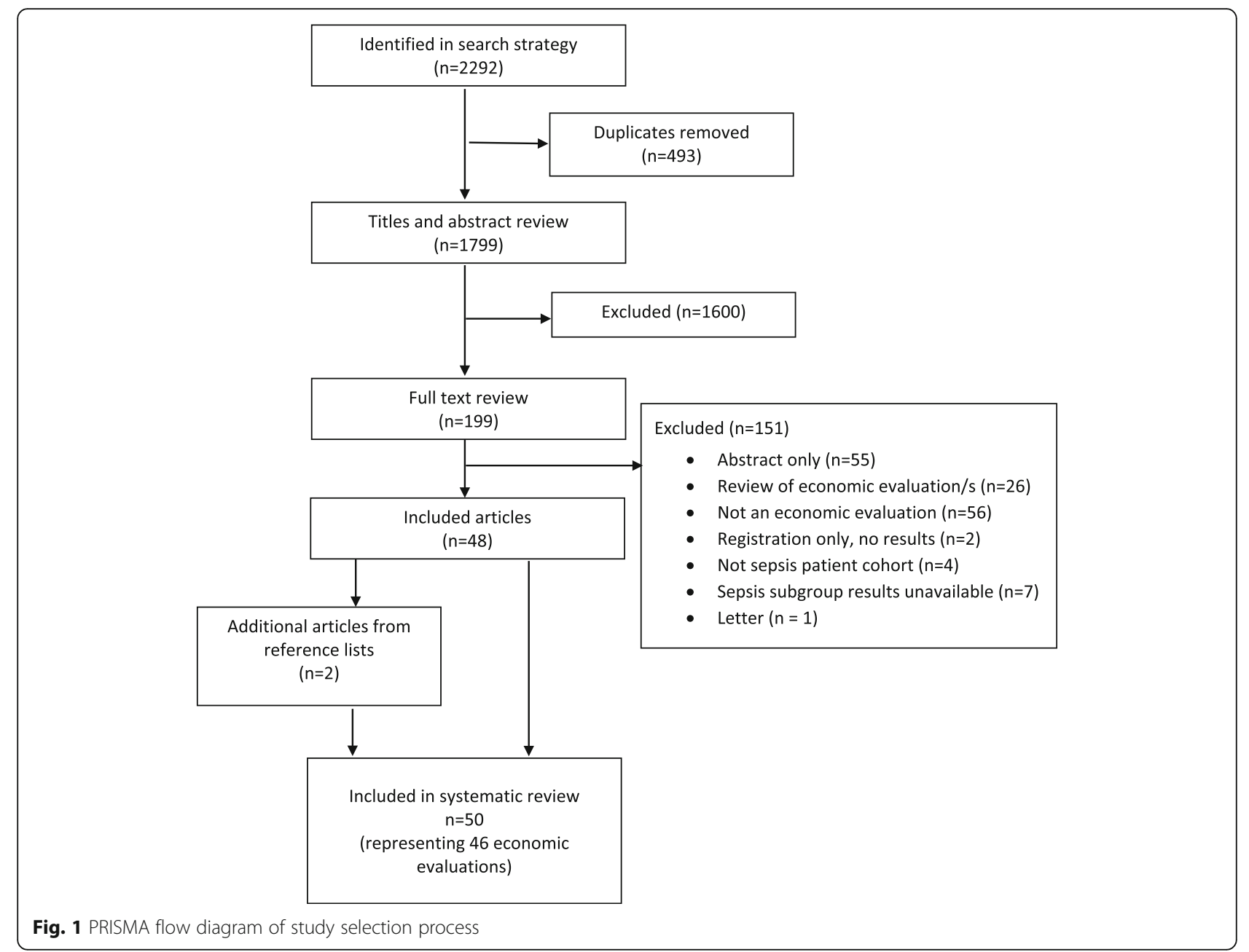

were trial-based evaluations, with 12 of those also using modelling to model variables not collected within the trial or extrapolate beyond the trial period. The remaining 28 evaluations used models synthesising data from various sources (Additional file 3: Table A3-1).

All evaluations were performed in patients with suspected or confirmed sepsis, with no evaluations using the updated definitions of sepsis published in 2016 [72]. The majority of evaluations were set in North America $(17 / 46,37 \%)$ and Europe $(23 / 46,50 \%)$, with only 4 (9\%) from low and middle income countries or regions $[22,39,40,48]$ (Table 1 ).

Most evaluations were performed from the perspective of the healthcare provider $(18 / 46,39 \%)$ with the perspective being unclear or not stated in $24 \%(11 / 46)$ of evaluations (Table 1). Of the 27 evaluations which explicitly stated a time horizon, the majority used a lifetime horizon (17/27, 63\%); however, 9 of these only reported costs for the initial hospitalisation. For the 19 evaluations that did not specifically state a time horizon, the majority (53\%) appeared to use a lifetime horizon. Only
10/46 (22\%) evaluations included costs incurred after hospital discharge.

Thirteen evaluations were funded by the manufacturer of the intervention being evaluated, while 14 were publicly funded. Eighteen evaluations did not report a funding source. The quality of reporting was comparable between those funded by the pharmaceutical industry $(11 / 13,85 \%)$ and those funded by government or not for profit organisations (12/13, 92\%). Among evaluations funded by the pharmaceutical industry, $92 \%(12 / 13)$ concluded that the intervention was cost-effective compared to $64 \%(9 / 14)$ funded by government or not for profit organisations (see Table 1 and Additional file 3). Sensitivity analyses to determine the level of confidence associated with the economic evaluation results were conducted in $89 \%(41 / 46)$ of evaluations (Additional file 4).

\section{Reporting quality}

The reporting quality varied widely, with scores ranging from $13 \%(3 / 23)$ [65] to 95\% (21/22) [42, 50]. Twelve (26\%) of the studies were found to be of excellent 
Table 1 General characteristics of included economic evaluations

\begin{tabular}{|c|c|c|}
\hline Evaluation characteristic & Evaluations $(n=46), n(\%)$ & Evaluation reference numbers \\
\hline \multicolumn{3}{|l|}{ Interventions } \\
\hline Antibiotic therapies & $5(11 \%)$ & {$[22-26]$} \\
\hline Fluid therapies & $2(4 \%)$ & {$[27,28]$} \\
\hline Procalcitonin algorithms & $3(7 \%)$ & [29-31] \\
\hline Immmunoglobulin therapies & $2(4 \%)$ & {$[32-34]$} \\
\hline EGDT or other sepsis protocol & $8(17 \%)$ & {$[35-43]$} \\
\hline Pathogen identification & $4(9 \%)$ & [44-47] \\
\hline Other & $2(4 \%)$ & {$[48,49]$} \\
\hline \multicolumn{3}{|c|}{ Interventions no longer in clinical practice } \\
\hline Drotrecogin alfa (activated) & $13(28 \%)$ & {$[50-64]$} \\
\hline Monoclonal antibodies & $7(15 \%)$ & {$[65-71]$} \\
\hline \multicolumn{3}{|l|}{ Type of evaluation } \\
\hline Cost-minimisation & $2(4 \%)$ & {$[25,44]$} \\
\hline Cost-effectiveness & $21(46 \%)$ & {$[22,24,26-28,30,32,39,45,49,52,54,59,61,64-71]$} \\
\hline Cost-utility & $9(20 \%)$ & {$[29,31,33,34,40-43,47,48,63]$} \\
\hline Cost-effectiveness and cost-utility & $14(30 \%)$ & {$[23,35-38,46,50,51,53,55-58,60,62]$} \\
\hline \multicolumn{3}{|l|}{ Country } \\
\hline USA & $15(33 \%)$ & {$[23,28,29,35-37,48,51-53,65,66,68,70,71]$} \\
\hline UK & $9(20 \%)$ & {$[25,31,33,34,41,42,47,57,58,62,63,69]$} \\
\hline Canada & $2(4 \%)$ & {$[50,59]$} \\
\hline France & $4(9 \%)$ & {$[27,45,56,60]$} \\
\hline Spain & $4(9 \%)$ & {$[38,44,54,67]$} \\
\hline Sweden & $1(2 \%)$ & {$[55]$} \\
\hline Greece & $1(2 \%)$ & [26] \\
\hline Italy & $1(2 \%)$ & [24] \\
\hline Netherlands & $1(2 \%)$ & {$[30]$} \\
\hline Germany & $2(4 \%)$ & {$[32,61,64]$} \\
\hline Russian Federation & $1(2 \%)$ & [22] \\
\hline Brazil & $2(4 \%)$ & {$[39,40]$} \\
\hline Thailand & $1(2 \%)$ & [49] \\
\hline Multinational & $2(4 \%)$ & {$[43,46]$} \\
\hline \multicolumn{3}{|l|}{ Evaluation perspective $^{1}$} \\
\hline Hospital & $11(24 \%)$ & {$[24,25,29,30,32,44,45,49,52,66,68]$} \\
\hline Healthcare system & $18(39 \%)$ & {$[27,28,33,34,36,38,40-43,46,47,50,54,57-62,64,71]$} \\
\hline Societal & $6(13 \%)$ & {$[23,35,51,53,65,70]$} \\
\hline Not stated & $11(24 \%)$ & {$[22,26,31,37,39,48,55,56,63,67,69]$} \\
\hline \multicolumn{3}{|l|}{ Time horizon ${ }^{2}$} \\
\hline ICU or Hospital stay & $2(4 \%)$ & {$[30,32]$} \\
\hline 28 or 30 days & $3(7 \%)$ & {$[45,52,71]$} \\
\hline 90 days & $1(2 \%)$ & [43] \\
\hline 6 months & $1(2 \%)$ & [31] \\
\hline 1 year & $1(2 \%)$ & [29] \\
\hline 20 years & $2(4 \%)$ & {$[41,42,59]$} \\
\hline Lifetime & $17(37 \%)$ & {$[23,24,33-36,38,39,47,50,51,53,56,61,63-67]$} \\
\hline
\end{tabular}


Table 1 General characteristics of included economic evaluations (Continued)

\begin{tabular}{lll}
\hline Evaluation characteristic & Evaluations $(n=46), n(\%)$ & Evaluation reference numbers \\
\hline $\begin{array}{l}\text { Not stated or unclear } \\
\text { Funder }\end{array}$ & $19(41 \%)$ & {$[22,25-28,37,40,44,46,48,49,54,55,57,58,60,62,68-70]$} \\
$\begin{array}{l}\text { Pharmaceutical company } \\
\text { Government or NFP }\end{array}$ & {$[3(28 \%)$} & {$[23,24,27,30,32,46,48,51,56,61,62,64,67,68]$} \\
No funding & $14(30 \%)$ & {$[25,26,31,33-35,37,38,41-43,45,47,50,57,58,60]$} \\
Not stated & $1(2 \%)$ & {$[53]$} \\
Reporting quality & $18(39 \%)$ & {$[22,28,29,36,39,40,44,49,54,55,59,63,65,66,69-71]$} \\
Excellent $(\geq 85 \%)$ & & {$[23,24,30,33-36,38,41,42,47,51,53,61,64]$} \\
Very good $(70$ to $<85 \%)$ & $12(26 \%)$ & {$[25,28,29,31,32,37,40,43,50,52,54,57-60,62,63,67,68]$} \\
Good $(55$ to $<70 \%)$ & $18(39 \%)$ & {$[22,39,44,45,48,49,55,56,65,70,71]$} \\
Poor $(<55 \%)$ & $11(24 \%)$ & {$[26,27,46,66,69]$} \\
\hline
\end{tabular}

EGDT early goal-directed therapy, ICU intensive care unit, NFP not for profit, UK United Kingdom, USA United States of America

${ }^{1}$ Where studies conducted analyses from more than one perspective, the broader perspective has been reported in the table

${ }^{2}$ Where studies conducted more than one analysis with different time horizons, the latest time horizon has been reported in the table

reporting quality, 18 (39\%) of very good quality, 11 (24\%) of good quality, and $5(11 \%)$ of poor quality. The quality of evaluations published in the past 15 years was higher (average $75 \%$ ) than evaluations published prior to 2005 (average 58\%), with the quality of evaluations varying by intervention-88\% of EGDT and resuscitation protocol evaluations were of very good or excellent quality compared to $60 \%$ of evaluations of antibiotic therapies and $25 \%$ of evaluations of pathogen identification (Additional file 4).

\section{Evaluation results}

For evaluations of interventions currently used in clinical practice, eight (31\%) studies reported incremental cost per life saved (LS) with ICERs ranging from dominant for EGDT [35, 39] to $\$ 80,852 / \mathrm{LS}$ (2006 €48,039/LS) for EGDT [38] (Table 2 and Additional file 3: Table A3-2). Seven studies (27\%) reported incremental cost per life years gained (LYG) with ICERs ranging from dominant for albumin (over hydroxyethyl starch) [28] to $\$ 25,565$ / LYG (2008 \$22,230/LYG) for empiric micafungin antibiotic therapy [23, 65]. Twelve (46\%) evaluations reported incremental cost per QALY with ICERs ranging from dominant for a multifaceted sepsis education program to improve compliance with the Surviving Sepsis Campaign bundle [40] and a procalcitonin-guided treatment algorithm [29, 31] to dominated for PCR testing [46] (see Table 2 and Additional file 3). Only seven (27\%) evaluations (of interventions in current clinical use) reported subgroup results for different illness severities with highly variable results (see Additional file 3: Table A3-3). One (4\%) evaluation reported an ICER using a different measure of effectiveness (cost per antibiotic day avoided) [30], while three (12\%) evaluations did not report an ICER or a probability of cost effectiveness $[22,25,43]$, including the two cost-minimisation evaluations. Among currently used interventions, 77\% $(20 / 26)$ of evaluations concluded that the intervention

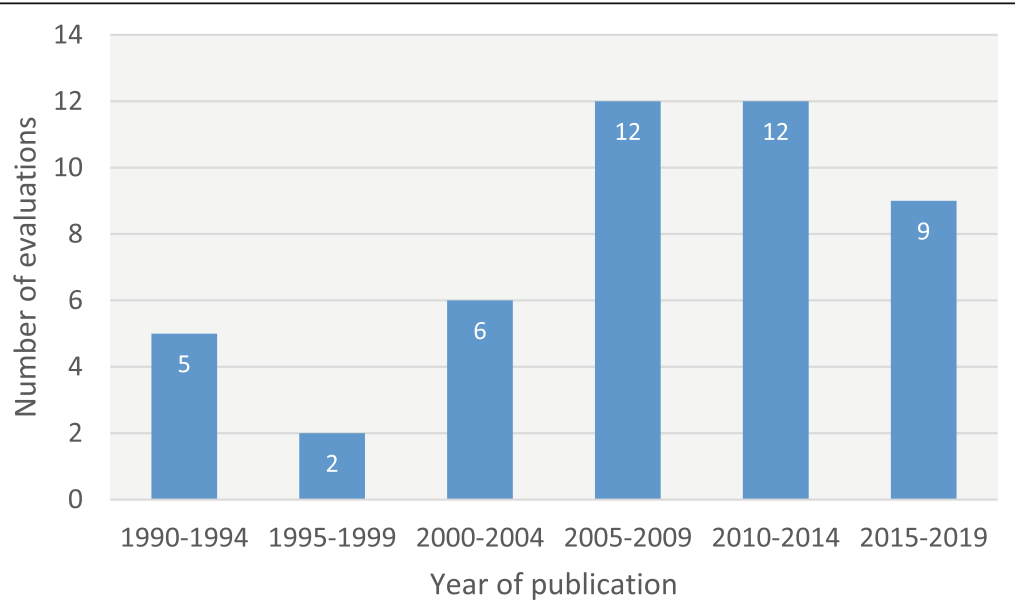

Fig. 2 Number of published economic evaluations by 5-year period 
Table 2 Cost-effectiveness results for sepsis interventions

\begin{tabular}{|c|c|c|c|c|c|c|}
\hline \multirow[b]{2}{*}{ Intervention } & \multicolumn{2}{|c|}{ Cost/LS (2018 USD) } & \multicolumn{2}{|c|}{ Cost/LYG (2018 USD) } & \multicolumn{2}{|c|}{ Cost/QALY (2018 USD) } \\
\hline & $n(\%)$ & Range & $n(\%)$ & Range & $n(\%)$ & Range \\
\hline Antibiotic therapies & $\begin{array}{l}1 \\
(20 \%)\end{array}$ & $\$ 70,663 / \mathrm{LS}$ & $2(40 \%)$ & $\$ 5,797 / \mathrm{LYG}$ to $\$ 25,565 / \mathrm{LYG}$ & $\begin{array}{l}1 \\
(20 \%)\end{array}$ & $\$ 39,944 / \mathrm{QALY}$ \\
\hline Fluid therapies & $\begin{array}{l}1 \\
(50 \%)\end{array}$ & $\$ 8,211 / \mathrm{LS}$ & $1(50 \%)$ & Dominant to $\$ 839 / \mathrm{LYG}$ & $0(0 \%)$ & Not reported \\
\hline Procalcitonin algorithms & $0(0 \%)$ & Not reported & $0(0 \%)$ & Not reported & $\begin{array}{l}2 \\
(67 \%)\end{array}$ & Dominant \\
\hline Immunoglobulin therapies & $\begin{array}{l}1 \\
(50 \%)\end{array}$ & $\$ 15,738 / \mathrm{LS}$ & $0(0 \%)$ & Not reported & $\begin{array}{l}1 \\
(50 \%)\end{array}$ & $\$ 34,362 / \mathrm{QALY}$ \\
\hline $\begin{array}{l}\text { EGDT or other sepsis } \\
\text { protocol }\end{array}$ & $\begin{array}{l}3 \\
(38 \%)\end{array}$ & Dominant to $\$ 80,852 / \mathrm{LS}$ & $3(38 \%)$ & $\$ 5,787 / \mathrm{LYG}$ to $\$ 14,981 / \mathrm{LYG}$ & $\begin{array}{l}5 \\
(63 \%)\end{array}$ & Dominant to $\$ 21,691 /$ QALY \\
\hline Pathogen identification & $\begin{array}{l}1 \\
(25 \%)\end{array}$ & $\$ 16,789 / \mathrm{LS}$ & $0(0 \%)$ & Not reported & $\begin{array}{l}2 \\
(50 \%)\end{array}$ & $\$ 2,199 /$ QALY to Dominated \\
\hline Other therapies & $\begin{array}{l}1 \\
(50 \%)\end{array}$ & $\$ 4,029 / \mathrm{LS}$ & $0(0 \%)$ & Not reported & $\begin{array}{l}1 \\
(50 \%)\end{array}$ & $\$ 34,984 / \mathrm{QALY}$ \\
\hline \multicolumn{7}{|c|}{ Interventions no longer in clinical practice } \\
\hline Drotecogin alfa (activated) & $\begin{array}{l}3 \\
(23 \%)\end{array}$ & $\begin{array}{l}\$ 79,418 / \mathrm{LS} \text { to } \$ 233,600 / \\
\text { LS }\end{array}$ & $\begin{array}{l}10 \\
(77 \%)\end{array}$ & $\$ 2,696 / L Y G$ to $\$ 48,618 / L Y G$ & $\begin{array}{l}9 \\
(69 \%)\end{array}$ & $\begin{array}{l}\$ 3,901 / \text { QALY to } \$ 71,248 / \\
\text { QALY }\end{array}$ \\
\hline Monoclonal antibodies & $\begin{array}{l}4 \\
(57 \%)\end{array}$ & $\begin{array}{l}\$ 24,719 / \text { LS to } \$ 379,579 / \\
\text { LS }\end{array}$ & $3(43 \%)$ & $\begin{array}{l}\$ 2,679 / L Y G \text { to } \$ 1,830,283 / \\
\text { LYG }\end{array}$ & $0(0 \%)$ & Not reported \\
\hline
\end{tabular}

$\overline{E G D T}$ early goal directed therapy, $L S$ life saved, $L Y G$ life years gained, $Q A L Y$ quality-adjusted life year, USD United States dollar

was cost-effective; however, some only concluded the intervention to be cost-effectiveness under certain conditions (e.g. higher severity of illness). Due to the significant variations in methodology and reporting quality, quantitative synthesis of study results was not performed.

In evaluations modelling life expectancy following sepsis $(n=32)$, most $(12 / 32,38 \%)$ used a single adjustment factor of 0.51 [73] to reduce age and gender-specific population life expectancy to account for the higher long-term mortality risk following sepsis $[23,35-38,40$, 50, 53-55, 59, 60]. Among the 23 cost-utility evaluations, the majority (61\%) used a single utility value multiplied by life expectancy to determine QALYs, and only one evaluation prospectively measured quality of life [42]. Most cost-utility evaluations varied utility weights in sensitivity analyses, with the majority finding that the utility weight (across the range varied) did not impact on conclusions about cost-effectiveness.

\section{Discussion}

We conducted a comprehensive systematic review of economic evaluations of sepsis interventions and identified 50 publications representing 46 economic evaluations. The evaluations were of a variety of interventions, some of which have since been shown to have no clinical benefit and are no longer in use (e.g. drotrecogin alfa [activated] and monoclonal antibodies). There was significant heterogeneity in design of the evaluations, including in the outcome measures used, the range of costs included, the time horizon, and the evaluation perspective. This prevented a quantitative synthesis of results, and interpretation of any such results would be unclear. The narrative synthesis of results indicated wide variation in ICERs.

Economic evaluations are constrained by limited availability of high quality evidence from randomised controlled trials (RCTs) and limited data on long term outcomes including quality of life. For health care decision makers to be able to make accurate decisions about the economic effects of sepsis interventions, sufficient data needs to be available. Existing studies of the longterm natural history of sepsis have typically had small sample sizes or low follow-up rates. Better characterisation of recovery following sepsis can reduce the need to make numerous assumptions about the trajectory of outcomes in economic evaluations of interventions in sepsis. Whilst clinical trials can provide effectiveness data with high internal validity, they are often limited in the range of resource use and outcome data collected, or the length of follow-up. As a result, most economic evaluations need to model resource use and/or longer-term outcomes (such as life expectancy) to determine the cost-effectiveness of the intervention. Only five of the evaluations included in our review did not have any modelling component. Sepsis is known to have long term consequences including a higher risk of readmissions, cardiovascular disease, cognitive impairment, and death [74]. Only 17 of the evaluations included in the review reported using a lifetime horizon (with a further 10 of 19 that did not state a time horizon appearing to use 
a lifetime horizon). However, despite evidence showing that $40 \%$ of sepsis patients will be readmitted to hospital within 90 days of discharge [75], 19 (70\%) of the evaluations with a stated or assumed lifetime horizon did not include any costs beyond the initial hospitalisation. In interventions that improve hospital survival, this may result in an overestimate of cost-effectiveness as the long-term healthcare costs of survivors are not included.

Many of the evaluations included in our review used data from non-randomised trials or from single-centre RCTs. For example, 6 of the 8 evaluations of EGDT and other sepsis protocols used data from a single-centre trial or from non-randomised pre-post studies. The reliance on economic evaluations using such data can result in an overrepresentation of the cost-effectiveness of an intervention. All pre-post studies and the single-centre EGDT RCT by Rivers and colleagues [76] showed a significant survival benefit at hospital discharge associated with sepsis protocols. The majority of economic evaluations assumed that the survival benefit was maintained over time. Three subsequent multi-centre RCTs of EGDT showed no survival benefit $[41,77,78]$, with subsequent removal of the recommendation for EGDT from the Surviving Sepsis Campaign guidelines [79]. All economic evaluations conducted prior to publication of the three multicentre RCTs concluded that EGDT and other sepsis protocols were cost-effective, with the two evaluations conducted following the multi-centre RCTs both concluding that EGDT was not cost-effective [41, 42, 71]. This example shows the problems that can arise when drawing conclusions about cost effectiveness from single-centre or non-randomised trials or where sufficient outcome data is unavailable.

Given the high morbidity and mortality from sepsis, the high economic burden, and the large numbers of clinical trials performed, relatively few economic evaluations have been performed of sepsis interventions. The Surviving Sepsis Campaign published evidence based guidelines for the treatment of sepsis with the aim of reducing mortality and morbidity [79]. In our review, we identified no economic evaluations for several of the interventions mentioned in the guidelines. The SSC guidelines recommend resuscitation with crystalloid fluid (with the addition of albumin when patients require substantial amounts of crystalloids); however, we identified only two economic evaluations of fluid therapy $[27,28]$, neither of which incorporated a measure of cost/QALY and one of which was poor quality [27]. The use of corticosteroids in sepsis has been a topic of immense interest, with numerous systematic reviews conducted [9-11]. One recent systematic review identified 42 RCTs of corticosteroids in sepsis [11], yet our review identified no economic evaluations of corticosteroids. The SSC guidelines recommend norepinephrine as the first choice vasopressor, and despite a recent systematic review identifying 32 RCTs of vasopressors for the treatment of septic shock [80], we found no economic evaluations for this intervention. These examples show the large gaps that exist in the literature for the costeffectiveness of many sepsis interventions. It is essential that the value for money of many routinely used sepsis interventions is determined.

Wilcox and colleagues recently summarised economic evaluations of interventions in critical care and despite searching the literature from 1993 to 2018, identified just 20 evaluations of sepsis interventions, compared to 46 evaluations of sepsis interventions in the current review [14]. Our review differs from that of Wilcox and colleagues in that we did not restrict our search by year of publication, language, or location of critically ill patients (Wilcox and colleagues limited their review to the ICU setting). Only two of the evaluations in the current review were published prior to 1993, and three were published in a language other than English and therefore not eligible in the review by Wilcox and colleagues. The additional evaluations identified in the current review were for a variety of interventions, including both evaluations of immunoglobulin therapies, and all five evaluations of antibiotic therapies (four of which were published in English).

A key strength of our review is that a comprehensive search strategy was developed, encompassing multiple electronic databases, increasing the likelihood of identifying all economic evaluations of sepsis interventions. Further, the current review did not limit the search by date or language of publication. Study selection, data extraction, and reporting quality assessment were independently undertaken by two reviewers. However, reviewers were not blinded to the authors or journal of publication which may have influenced results, particularly when completing the reporting quality checklist. The quality assessment tool used in the review, the CHEERS checklist, indicated that the reporting quality of $89 \%$ of the included economic evaluations was good to excellent. However, while the CHEERS checklist assesses quality of the reporting of various aspects of an economic evaluation, it does not assess the suitability of the methodology reported, nor the quality of the data that was used to inform the economic evaluation.

Our review did not identify any economic evaluations of interventions using the current sepsis-3 definitions (sepsis-3) [72]. As an inclusion criterion of the current review was that the economic evaluation was in critically ill septic patients, it is likely that patients in most of the evaluations would meet current sepsis definitions. It is not possible, however, to determine the impact of the new definitions on the economic evaluation results given the data available. Future economic evaluations should ensure that the included population meets current sepsis definitions. 


\section{Conclusions}

This systematic review identified considerable heterogeneity in the design of economic evaluations for interventions in sepsis and wide variation in reported results. It also identified important gaps in the literature, with no economic evaluations identified for several interventions routinely used in sepsis. Given the high economic and social burden of sepsis, high quality economic evaluations are needed to increase our understanding of the cost-effectiveness of these interventions in routine clinical practice and to inform decision makers.

\section{Supplementary information}

Supplementary information accompanies this paper at https://doi.org/10. 1186/s40560-019-0412-2

Additional file 1. MEDLINE, Embase and Cochrane library search strategies

Additional file 2. Publications excluded at full text stage

Additional file 3. Tables A3-1 to A3-3 Characteristics and results of included evaluations

Additional file 4. CHEERS checklist and assessment of included economic evaluations

\section{Abbreviations}

CHEERS: Consolidated Health Economic Evaluation Reporting Standards; EGDT: Early goal-directed therapy; ICER: Incremental cost-effectiveness ratio; ICU: Intensive care unit; LS: Lives saved; LYG: Life years gained;

PCR: Polymerase chain reaction; PRISMA: Preferred Reporting Items for Systematic Reviews and Meta-Analyses; QALY: Quality-adjusted life year; USA: United States of America; USD: US dollars

\section{Acknowledgements}

We thank Polina Putrik, Nicolau Martin Bassols, Rongbin Xu, and Peng Xinyu for assistance with translation of non-English articles.

\section{Authors' contributions}

$A M H, D J C$, and $A H$ conceived the study. $A M H$ and JB designed the study. $\mathrm{AMH}, \mathrm{JB}$, and $\mathrm{MM}$ acquired the data. $\mathrm{AMH}$ and $\mathrm{JB}$ analysed and interpreted the data. $A M H$ drafted the manuscript. JB, MM, AH, and DJC critically revised the manuscript. All authors read and approved the final manuscript.

\section{Funding}

Ms Higgins was supported to complete this work by a National Health and Medical Research Council post-graduate scholarship (No 579709). D. Jamie Cooper (DJC) was supported by an NHMRC Practitioner Fellowship.

\section{Availability of data and materials}

Available from the corresponding author on reasonable request.

\section{Ethics approval and consent to participate}

Not applicable.

\section{Consent for publication}

Not applicable.

\section{Competing interests}

The authors declare that they have no competing interests.

\section{Author details}

${ }^{1}$ Australian and New Zealand Intensive Care Research Centre, Department of Epidemiology and Preventive Medicine, Monash University, 553 St Kilda Rd, Melbourne, Victoria 3004, Australia. ${ }^{2}$ Department of Intensive Care and Hyperbaric Medicine, The Alfred, Melbourne, Victoria, Australia. ${ }^{3}$ Centre for Health Economics, Monash University, Melbourne, Victoria, Australia.
Received: 14 August 2019 Accepted: 31 October 2019

Published online: 08 January 2020

\section{References}

1. Reinhart K, Daniels R, Kissoon N, Machado FR, Schachter RD, Finfer S. Recognizing sepsis as a global health priority - a WHO resolution. N Engl J Med. 2017;377(5):414-7.

2. Torio CM, Moore BJ. National inpatient hospital costs: the most expensive conditions by payer, 2013. HCUP Statistical Brief \#204. Rockville, MD: Agency for Healthcare Research and Quality; 2016

3. Angus DC, Barnato AE, Bell D, Bellomo R, Chong CR, Coats TJ, et al. A systematic review and meta-analysis of early goal-directed therapy for septic shock: the ARISE, ProCESS and ProMISe Investigators. Intensive Care Med. 2015:41(9):1549-60

4. Simpson SQ, Gaines M, Hussein Y, Badgett RG. Early goal-directed therapy for severe sepsis and septic shock: a living systematic review. J Crit Care. 2016;36:43-8.

5. Xu JY, Chen QH, Liu SQ, Pan C, Xu XP, Han JB, et al. The effect of early goaldirected therapy on outcome in adult severe sepsis and septic shock patients: a meta-analysis of randomized clinical trials. Anesth Analg. 2016; 123(2):371-81

6. Delaney AP, Dan A, McCaffrey J, Finfer S. The role of albumin as a resuscitation fluid for patients with sepsis: a systematic review and metaanalysis. Crit Care Med. 2011:39(2):386-91.

7. Haase N, Perner A, Hennings LI, Siegemund M, Lauridsen B, Wetterslev M, et al. Hydroxyethyl starch 130/0.38-0.45 versus crystalloid or albumin in patients with sepsis: systematic review with meta-analysis and trial sequential analysis. BMJ. 2013;346:f839.

8. Rochwerg B, Alhazzani W, Sindi A, Heels-Ansdell D, Thabane L, FoxRobichaud A, et al. Fluid resuscitation in sepsis: a systematic review and network meta-analysis. Ann Intern Med. 2014;161(5):347-55.

9. Annane D, Bellissant E, Bollaert PE, Briegel J, Confalonieri M, De Gaudio R, et al. Corticosteroids in the treatment of severe sepsis and septic shock in adults: a systematic review. JAMA. 2009;301(22):2362-75.

10. Gibbison B, Lopez-Lopez JA, Higgins JP, Miller T, Angelini GD, Lightman SL, et al. Corticosteroids in septic shock: a systematic review and network metaanalysis. Crit Care. 2017:21(1):78

11. Rochwerg B, Oczkowski SJ, Siemieniuk RAC, Agoritsas T, Belley-Cote E, D'Aragon F, et al. Corticosteroids in sepsis: an updated systematic review and meta-analysis. Crit Care Med. 2018;46(9):1411-20.

12. Higgins $\mathrm{AM}$, Harris $\mathrm{AH}$. Health economic methods: cost-minimization, costeffectiveness, cost-utility, and cost-benefit evaluations. Crit Care Clin. 2012; 28(1):11-24 v.

13. Talmor D, Shapiro N, Greenberg D, Stone PW, Neumann PJ. When is critical care medicine cost-effective? A systematic review of the cost-effectiveness literature. Crit Care Med. 2006:34(11):2738-47.

14. Wilcox ME, Vaughan K, Chong C, Neumann PJ, Bell CM. Cost-effectiveness studies in the ICU: a systematic review. Crit Care Med. 2019:47(8):1011-7.

15. Moher D, Liberati A, Tetzlaff J, Altman DG, Group P. Preferred reporting items for systematic reviews and meta-analyses: the PRISMA statement. PLoS Med. 2009;6(7):e1000097.

16. Drummond M, Schulpher M, Claxton K, Stoddart G, Torrance G. Methods for the economic evaluation of health care programmes: Oxford University Press; 2015.

17. Husereau D, Drummond M, Petrou S, Carswell C, Moher D, Greenberg D, et al. Consolidated Health Economic Evaluation Reporting Standards (CHEERS) statement. BMJ. 2013;346:f1049.

18. Husereau D, Drummond M, Petrou S, Carswell C, Moher D, Greenberg D, et al. Consolidated Health Economic Evaluation Reporting Standards (CHEERS)--explanation and elaboration: a report of the ISPOR Health Economic Evaluation Publication Guidelines Good Reporting Practices Task Force. Value Health. 2013;16(2):231-50.

19. Hope SF, Webster J, Trieu K, Pillay A, leremia M, Bell C, et al. A systematic review of economic evaluations of population-based sodium reduction interventions. PLoS One. 2017:12(3):e0173600.

20. PPP conversion factor, GDP (LCU per international \$), International Comparison Program database [Internet]. The World Bank Group. [cited July 29 2019]. Available from: https://data.worldbank.org/indicator/PA.NUS. PPP?name desc=true

21. CPI Inflation Calculator [Internet]. United States Department of Labor. [cited 29 July 2019]. Available from: https://www.bls.gov/data/inflation calculator.htm. 
22. Yakovlev SV, Beloborodov VB, Sidorenko SV, Yakovlev VP, Grigoryev KB, Eliseeva EV, et al. Multicentre study of comparative efficacy of meropenem and combined regimens for empirical antibacterial therapy of severe nosocomial infections: results of clinical and pharmacoeconomic analysis. [Russian]. Antibiotiki i Khimioterapiya. 2006;51(7):15-27.

23. Zilberberg MD, Kothari S, Shorr AF. Cost-effectiveness of micafungin as an alternative to fluconazole empiric treatment of suspected ICU-acquired candidemia among patients with sepsis: a model simulation. Critical Care (London, England). 2009;13(3):R94.

24. Berto P, Ronco C, Cruz D, Melotti RM, Antonelli M. Cost-effectiveness analysis of polymyxin-B immobilized fiber column and conventional medical therapy in the management of abdominal septic shock in Italy. Blood Purification. 2011:32(4):331-40.

25. Scawn N, Saul D, Pathak D, Matata B, Kemp I, Stables R, et al. A pilot randomised controlled trial in intensive care patients comparing 7 days' treatment with empirical antibiotics with 2 days' treatment for hospital-acquired infection of unknown origin. Health Technology Assessment. 2012;16(36):i-xiii+1.

26. Tsaganos T, Raftogiannis M, Pratikaki M, Christodoulou S, Kotanidou A,

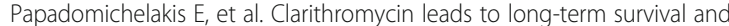
cost benefit in ventilator-associated pneumonia and sepsis. Antimicrobial Agents \& Chemotherapy. 2016;60(6):3640-6.

27. Guidet B, Mosqueda GJ, Priol G, Aegerter P. The COASST study: costeffectiveness of albumin in severe sepsis and septic shock. Journal of Critical Care. 2007;22(3):197-203.

28. Farrugia A, Bansal M, Balboni S, Kimber MC, Martin GS, Cassar J. Choice of fluids in severe septic patients - a cost-effectiveness analysis informed by recent clinical trials. Reviews on Recent Clinical Trials. 2014;9(1):21-30.

29. Harrison $M$, Collins CD. Is procalcitonin-guided antimicrobial use costeffective in adult patients with suspected bacterial infection and sepsis? Infection Control \& Hospital Epidemiology. 2015;36(3):265-72.

30. Kip MM, Kusters R, IJ MJ, Steuten LM. A PCT algorithm for discontinuation of antibiotic therapy is a cost-effective way to reduce antibiotic exposure in adult intensive care patients with sepsis. Journal of Medical Economics. 2015;18(11):944-53.

31. Westwood M, Ramaekers B, Whiting P, Tomini F, Joore M, Armstrong N, et al. Procalcitonin testing to guide antibiotic therapy for the treatment of sepsis in intensive care settings and for suspected bacterial infection in emergency department settings: a systematic review and cost-effectiveness analysis. Health Technology Assessment (Winchester, England). 2015;19(96):V-XXV, 1.

32. Neilson AR, Burchardi $H$, Schneider $H$. Cost-effectiveness of immunoglobulin M-enriched immunoglobulin (Pentaglobin) in the treatment of severe sepsis and septic shock. Journal of Critical Care. 2005;20(3):239-49.

33. Soares MO, Welton NJ, Harrison DA, Peura P, Hari MS, Harvey SE, et al. An evaluation of the feasibility, cost and value of information of a multicentre randomised controlled trial of intravenous immunoglobulin for sepsis (severe sepsis and septic shock): Incorporating a systematic review, metaanalysis and value of information analysis. Health Technology Assessment. 2012;16(7).

34. Soares MO, Welton NJ, Harrison DA, Peura P, Shankar-Hari M, Harvey SE, et al. Intravenous immunoglobulin for severe sepsis and septic shock: clinical effectiveness, cost-effectiveness and value of a further randomised controlled trial. Critical Care (London, England). 2014;18(6):649.

35. Huang DT, Clermont G, Dremsizov T, Angus DC, Pro Cl. Implementation of early goal-directed therapy for severe sepsis and septic shock: a decision analysis. Critical Care Medicine. 2007;35(9):2090-100.

36. Talmor D, Greenberg D, Howell MD, Lisbon A, Novack V, Shapiro N. The costs and cost-effectiveness of an integrated sepsis treatment protocol. Critical Care Medicine. 2008;36(4):1168-74.

37. Jones AE, Troyer JL, Kline JA. Cost-effectiveness of an emergency departmentbased early sepsis resuscitation protocol. Critical Care Medicine. 2011;39(6):1306-12.

38. Suarez D, Ferrer R, Artigas A, Azkarate I, Garnacho-Montero J, Goma G, et al. Cost-effectiveness of the Surviving Sepsis Campaign protocol for severe sepsis: a prospective nation-wide study in Spain. Intensive Care Medicine. 2011;37(3):444-52.

39. Assuncao MS, Teich V, Shiramizo SC, Araujo DV, Carrera RM, Serpa Neto A, et al. The cost-effectiveness ratio of a managed protocol for severe sepsis. Journal of Critical Care. 2014;29(4):692.e1-6.

40. Noritomi DT, Ranzani OT, Monteiro MB, Ferreira EM, Santos SR, Leibel F, et al. Implementation of a multifaceted sepsis education program in an emerging country setting: clinical outcomes and cost-effectiveness in a long-term follow-up study. Intensive Care Medicine. 2014;40(2):182-91.
41. Mouncey PR, Osborn TM, Power GS, Harrison DA, Sadique MZ, Grieve RD, et al. Trial of early, goal-directed resuscitation for septic shock. New England Journal of Medicine. 2015;372(14):1301-11.

42. Mouncey PR, Osborn TM, Power GS, Harrison DA, Sadique MZ, Grieve RD, et al. Protocolised Management In Sepsis (ProMISe): a multicentre randomised controlled trial of the clinical effectiveness and cost-effectiveness of early, goal-directed, protocolised resuscitation for emerging septic shock. Health Technology Assessment (Winchester, England). 2015;19(97):i-Xxv, 1.

43. Prism I, Rowan KM, Angus DC, Bailey M, Barnato AE, Bellomo R, et al. Early, Goal-directed therapy for septic shock - a patient-level meta-analysis. New England Journal of Medicine. 2017;376(23):2223-34.

44. Alvarez J, Mar J, Varela-Ledo E, Garea M, Matinez-Lamas L, Rodriguez J, et al. Cost analysis of real-time polymerase chain reaction microbiological diagnosis in patients with septic shock. Anaesthesia \& Intensive Care. 2012; 40(6):958-63.

45. Cambau E, Durand-Zaleski I, Bretagne S, Brun-Buisson C, Cordonnier C, Duval $\mathrm{X}$, et al. Performance and economic evaluation of the molecular detection of pathogens for patients with severe infections: the EVAMICA open-label, cluster-randomised, interventional crossover trial. Intensive Care Medicine. 2017;43(11):1613-25.

46. Lehmann LE, Herpichboehm B, Kost GJ, Kollef MH, Stuber F. Cost and mortality prediction using polymerase chain reaction pathogen detection in sepsis: evidence from three observational trials. Critical Care (London, England). 2010;14(5):R186.

47. Stevenson M, Pandor A, Martyn-St James M, Rafia R, Uttley L, Stevens J, et al. Sepsis: the LightCycler SeptiFast Test MGRADE, SepsiTestTM and IRIDICA BAC BSI assay for rapidly identifying bloodstream bacteria and fungi - a systematic review and economic evaluation. Health Technology Assessment (Winchester, England). 2016;20(46):1-246.

48. Ward MJ, Self WH, Singer A, Lazar D, Pines JM. Cost-effectiveness analysis of early point-of-care lactate testing in the emergency department. Journal of Critical Care. 2016;36:69-75.

49. Champunot R, Thawitsri T, Kamsawang N, Sirichote V, Nopmaneejumruslers C. Cost effectiveness analysis of an initial ICU admission as compared to a delayed ICU admission in patients with severe sepsis or in septic shock. Journal of the Medical Association of Thailand. 2014;97(Suppl 1):S102-7.

50. Manns BJ, Lee H, Doig CJ, Johnson D, Donaldson C. An economic evaluation of activated protein $C$ treatment for severe sepsis. New England Journal of Medicine. 2002;347(13):993-1000.

51. Angus DC, Linde-Zwirble WT, Clermont G, Ball DE, Basson BR, Ely EW, et al. Cost-effectiveness of drotrecogin alfa (activated) in the treatment of severe sepsis. Critical Care Medicine. 2003;31(1):1-11.

52. Betancourt M, McKinnon PS, Massanari RM, Kanji S, Bach D, Devlin JW. An evaluation of the cost effectiveness of drotrecogin alfa (activated) relative to the number of organ system failures. Pharmacoeconomics. 2003;21(18):1331-40.

53. Fowler RA, Hill-Popper M, Stasinos J, Petrou C, Sanders GD, Garber AM. Cost-effectiveness of recombinant human activated protein $C$ and the influence of severity of illness in the treatment of patients with severe sepsis. Journal of Critical Care. 2003;18(3):181-91 discussion 91.

54. Sacristan JA, Prieto L, Huete T, Artigas A, Badia X, Chinn C, et al. Costeffectiveness of drotrecogin alpha [activated] in the treatment of severe sepsis in Spain. [Spanish] Coste-efectividad de drotrecogina alfa (activada) en el tratamiento de la sepsis grave en Espana. Gaceta sanitaria / SESPAS. 2004;18(1):50-7.

55. Hjelmgren J, Persson U, Tennvall GR. Local treatment pattern versus trialbased data: a cost-effectiveness analysis of drotrecogin alfa (activated) in the treatment of severe sepsis in Sweden. American Journal of Therapeutics. 2005;12(5):425-30.

56. Franca LR, Launois $R$, Le Lay $K$, Aegerter $P$, Bouhassira M, Meshaka $P$, et al. Cost-effectiveness of drotrecogin alfa (activated) in the treatment of severe sepsis with multiple organ failure. International Journal of Technology Assessment in Health Care. 2006;22(1):101-8.

57. Green C, Dinnes J, Takeda A, Shepherd J, Hartwell D, Cave C, et al. Clinical effectiveness and cost-effectiveness of drotrecogin alfa (activated) (Xigris) for the treatment of severe sepsis in adults: a systematic review and economic evaluation. Health Technology Assessment (Winchester, England). 2005;9(11):1-126, iii.

58. Green C, Dinnes J, Takeda AL, Cuthbertson BH. Evaluation of the costeffectiveness of drotrecogin alfa (activated) for the treatment of severe sepsis in the United Kingdom. International Journal of Technology Assessment in Health Care. 2006;22(1):90-100. 
59. Costa V, Brophy JM. Drotrecogin alfa (activated) in severe sepsis: a systematic review and new cost-effectiveness analysis. BMC Anesthesiology. 2007;7:5.

60. Dhainaut JF, Payet $S$, Vallet B, Franca LR, Annane D, Bollaert PE, et al. Costeffectiveness of activated protein $C$ in real-life clinical practice. Critical Care (London, England). 2007;11(5):R99.

61. Neilson AR, Burchardi H, Chinn C, Clouth J, Schneider H, Angus D. Costeffectiveness of drotrecogin alfa (activated) for the treatment of severe sepsis in Germany.[Erratum appears in J Crit Care. 2004 Mar;19(1):66]. Journal of Critical Care. 2003;18(4):217-27.

62. Davies A, Ridley S, Hutton J, Chinn C, Barber B, Angus DC. Cost effectiveness of drotrecogin alfa (activated) for the treatment of severe sepsis in the United Kingdom. Anaesthesia. 2005;60(2):155-62.

63. Sadique MZ, Grieve R, Harrison DA, Cuthbertson BH, Rowan KM. Is Drotrecogin alfa (activated) for adults with severe sepsis, cost-effective in routine clinical practice? Critical Care (London, England). 2011;15(5):R228.

64. Neilson, Burchardi, Chinn. Erratum: cost-effectiveness of drotrecogin alfa (Activated) for the treatment of severe sepsis in Germany (Journal of Critical Care (18) (217-227)). Journal of Critical Care. 2004;19(1):66.

65. Schulman KA, Glick HA, Rubin H, Eisenberg JM. Cost-effectiveness of ha-1a monoclonal antibody for gram-negative sepsis: Economic assessment of a new therapeutic agent. JAMA. 1991;266(24):3466-71.

66. Barriere SL. The economic impact of HA-1A (Centoxin) against endotoxin. Pharmacoeconomics. 1992;2(5):408-13.

67. Badia X, Segu L, Garcia Alonso F, Rovira J. A cost-efficacy analysis of treatment with antiendotoxin monoclonal antibodies in gram-negative sepsis. Medicina Clinica. 1993;100(3):84-9.

68. Chalfin DB, Holbein ME, Fein AM, Carlon GC. Cost-effectiveness of monoclonal antibodies to gram-negative endotoxin in the treatment of gram-negative sepsis in ICU patients. JAMA. 1993;269(2):249-54.

69. Chang RWS, Beale R, Smithies M, Bihari D. A preliminary cost-performance evaluation of HA-1A (Centoxin) with an addendum on its demise. Clinical Intensive Care. 1993;4(5):208-16.

70. Linden PK, Angus DC, Chelluri L, Branch RA. The influence of clinical study design on cost-effectiveness projections for the treatment of gram-negative sepsis with human anti-endotoxin antibody. J Crit Care. 1995;10(4):154-64.

71. Wang EC, Grasela TH, Walawander CA. Applying epidemiology-based outcomes research to clinical decision-making. A hypothetical model of biotechnology therapy in gram-negative sepsis. Pharmacoeconomics. 1999; 15(4):385-93.

72. Singer M, Deutschman CS, Seymour CW, Shankar-Hari M, Annane D, Bauer $M$, et al. The Third International Consensus Definitions for Sepsis and Septic Shock (Sepsis-3). JAMA. 2016;315(8):801-10.

73. Quartin AA, Schein RM, Kett DH, Peduzzi PN. Magnitude and duration of the effect of sepsis on survival. Department of Veterans Affairs Systemic Sepsis Cooperative Studies Group. JAMA. 1997;277(13):1058-63.

74. Shankar-Hari M, Rubenfeld GD. Understanding long-term outcomes following sepsis: implications and challenges. Curr Infect Dis Rep. 2016; 18(11):37.

75. Prescott $\mathrm{HC}$, Angus DC. Enhancing recovery from sepsis: a review. JAMA. 2018;319(1):62-75

76. Rivers E, Nguyen B, Havstad S, Ressler J, Muzzin A, Knoblich B, et al. Early goal-directed therapy in the treatment of severe sepsis and septic shock. N Engl J Med. 2001;345(19):1368-77.

77. Investigators A, Group ACT, Peake SL, Delaney A, Bailey M, Bellomo R, et al. Goal-directed resuscitation for patients with early septic shock. N Engl J Med. 2014;371(16):1496-506.

78. Angus DC, van der Poll T. Severe sepsis and septic shock. N Engl J Med. 2013:369(21):2063.

79. Rhodes A, Evans LE, Alhazzani W, Levy MM, Antonelli M, Ferrer R, et al. Surviving Sepsis Campaign: International Guidelines for Management of Sepsis and Septic Shock: 2016. Crit Care Med. 2017;45(3):486-552.

80. Avni T, Lador A, Lev S, Leibovici L, Paul M, Grossman A. Vasopressors for the treatment of septic shock: systematic review and meta-analysis. PLoS One. 2015;10(8):e0129305.

\section{Publisher's Note}

Springer Nature remains neutral with regard to jurisdictional claims in published maps and institutional affiliations.

Ready to submit your research? Choose BMC and benefit from:
- fast, convenient online submission
- thorough peer review by experienced researchers in your field
- rapid publication on acceptance
- support for research data, including large and complex data types
- gold Open Access which fosters wider collaboration and increased citations
- maximum visibility for your research: over 100M website views per year
At BMC, research is always in progress.
Learn more biomedcentral.com/submissions

